\title{
Effects of an herbal extract composed of white tea, roasted yerba mate and fermented rooibos on the antioxidant activity and sensory properties of popsicles manufactured with different protein sources
}

\author{
Jânio Sousa Santos ${ }^{a^{*}}$, André Serenato Leal ${ }^{\mathrm{a}}$, Graziela Bragueto Eschera, \\ Adriano Gomes Cruz ${ }^{\mathrm{b}}$, Thiago Mendanha Cruz ${ }^{\mathrm{c}}$, Jarkko Hellström ${ }^{\mathrm{c}}$, \\ Juha-Matti Pihlava ${ }^{c}$ and Daniel Granato ${ }^{c^{*}}$
}

\begin{abstract}
aDepartment of Food Engineering, State University of Ponta Grossa (UEPG). Av. Carlos Cavalcanti, 4748, 84030-900, Ponta Grossa, Brazil

${ }^{b}$ Federal Institute of Education, Science and Technology from Rio de Janeiro (IFRJ), 20270-021, Rio de Janeiro, Brazil

'Food Processing and Quality, Innovative Food System, Production Systems Unit, Natural Resources Institute Finland (Luke), FI-02150 Espoo, Finland

*Corresponding author: Jânio Sousa Santos and Daniel Granato, Department of Food Engineering, State University of Ponta Grossa (UEPG). Av. Carlos Cavalcanti, 4748, 84030-900, Ponta Grossa, Brazil; Food Processing and Quality, Innovative Food System, Production Systems Unit, Natural Resources Institute Finland (Luke), FI-02150 Espoo, Finland. E-mail: santosjs.food@gmail.com and daniel.granato@luke.fi DOI: $10.31665 /$ JFB. 2020.11240

Received: July 31, 2020; Revised received \& accepted: September 11, 2020

Citation: Santos, J.S., Leal, A.S., Escher, G.B., Cruz, A.G., Cruz, T.M., Hellström, J., Pihlava, J.-M., and Granato, D. (2020). Effects of an herbal extract composed of white tea, roasted yerba mate and fermented rooibos on the antioxidant activity and sensory properties of popsicles manufactured with different protein sources. J. Food Bioact. 11: 84-94.
\end{abstract}

\begin{abstract}
Popsicle-type edible ice cream is consumed worldwide for its sensory properties. However, its nutritional composition is limited to carbohydrates, sweeteners and synthetic flavors. In this work, the objective was to develop popsicles manufactured with different protein sources (rice protein, concentrated bovine milk whey protein and a mixture of both proteins) and added with an herbal lyophilized extract (LME) composed of white tea, fermented rooibos, and roasted yerba mate. Six formulations were produced and their proximate composition, physicochemical properties, sensory acceptability, total phenolic content, condensed tannins, and in vitro antioxidant activity determined. Popsicles added with LME showed a higher total phenolic content compared to the controls (without LME). The popsicles formulated with animal protein and LME showed the highest antioxidant activity as measured by the DPPH and FRAP assays. In relation to sensory analysis, the highest acceptance rates, 91 and $88 \%$, were observed in formulations added with animal protein without and with LME, respectively. On the other hand, the vegan formulation added with LME had the lowest acceptance rate (69\%). Overall, the addition of LME and concentrated bovine whey protein provides a viable option for the development of phenolic-rich protein-based popsicles.
\end{abstract}

Keywords: Technology application; Vegetarian diet; Dairy desserts; Food development; Popsicle.

1. Introduction

Ice creams are defined as frozen products obtained from an emul- sion of fats and proteins; or a mixture of water and sugar. Other ingredients can be added as long as they do not mischaracterize the product (Brasil, 2005). The production of edible ice cream in Brazil has shown stability in recent years. According to the Brazilian 
Ice Cream Industry Association-ABIS, Brazil currently has roughly 8,000 ice cream producers. The sector generates about 75,000 direct and 200,000 indirect jobs, with annual revenues above US\$ 2.5 billion (ABIS, 2020). Frozen desserts, such as popsicles, are popular around the world because of their sweet taste, versatility in terms of formulations and refreshing sensation.

Popsicles and conventional ice creams are marketed in various forms such as conventional ones, light, fat-free, and low sugar content among others (Granato et al., 2018). Recent studies encourage the addition of plant-based extracts, which are sources of bioactive compounds, in ice cream and other dairy products to replace synthetic preservatives and taste agents (Öztürk et al., 2018). Martins et al. (2018) evaluated the bioactivity, chemical and sensory characteristics of popsicles manufactured with bovine milk whey protein and concentrated watermelon juice. According to these authors, the popsicles were sensorially acceptable and presented antioxidant activity. In fact, a diversity of herbal extracts has been studied in relation to their bioactivity, such as antioxidative, anti-obesity, and anti-allergic effects, among others (Khan and Mukhtar, 2019).

The health outcomes of plant-based diets have been increasingly recognized for presenting several benefits in both the short and long term (Satija and Hu, 2018). For instance, Patel et al. (2017) reported that plant-based diets decrease some risk factors and mortality from cardiovascular diseases and should be a therapeutic goal in patient care. Ferdowsian and Barnard (2009) performed a biographical survey regarding the effects of plant-based diets had on plasma lipids. Results showed that individuals who chose to follow plant-based diets have significantly lower blood lipid concentrations compared with those who follow milk, egg and meat-based diets. Recently, AdevaAndany et al. (2019) concluded that reduction in consumption of animal-based foods is beneficial in decreasing the risk of type 2 diabetes.

A recent study conducted by Santos et al. (2018) described the characterization of an herbal extract that is composed of $82.9 \% \mathrm{Ca}$ mellia sinensis (while tea), 10.9\% Ilex paraguariensis (roasted yerba mate) and 6.2\% Aspalathus linearis (fermented rooibos). This mixture presented a total phenolic content of $1,200 \mathrm{mg} / \mathrm{L}$ and high antioxidant activity measured by different chemical and cell-based assays. The beverage showed antibacterial activity and antiproliferative effects against human cancer cell lines (Caco-2 and HepG2). However, there is no application of this mixture on the manufacture of ice creams or other related desserts. In addition, the lyophilized extract composed of $82.9 \%$ white tea, $10.9 \%$ roasted yerba mate and $6.2 \%$ fermented rooibos showed toxicological safety, antioxidant, anti-hyperglycemic, and antihypertensive potential using different in vitro methodologies (Santos et al., 2020). However, there is no technological application of this bioactive-rich extract in food models.

Natural extracts made of herbs, edible flowers and other sources of bioactive compounds should be further explored by the food industry, in particular, for the development of products with a lower content (or absence) of synthetic additives, such as flavorings, antioxidants and antimicrobial agents (Granato et al., 2018). Thus, considering the demand for natural products and the technological need to develop nutritionally balanced foods, this work is aimed at developing popsicles that are sources of proteins and natural antioxidants, without the addition of artificial sweeteners/flavors, and to evaluate their nutritional, sensory acceptance and antioxidant activity.

\section{Materials and methods}

\subsection{Chemicals}

Folin-Ciocalteau reagent, DPPH (2,2-diphenyl-1-picrylhydrazyl), gallic acid, (+)-catechin, vanillin, TPTZ (2,4,6-tris (2-pyridyl)-Striazine), ferric chloride hexahydrate, and quercetin were obtained from Sigma-Aldrich (São Paulo, Brazil). Hydrochloric acid, sodium acetate, potassium ferricyanide, ascorbic acid, isobutanol, absolute ethanol, methanol and acetic (glacial) acid were purchased from Vetec (Rio de Janeiro, Brazil). Sodium hydroxide was purchased from Synth (Diadema, Brazil). Aqueous solutions were prepared using ultrapure water. For the formulation of popsicles, mineral water (Royal Fit, Ponta Grossa, Brazil), organic sucrose (Native, Sertãozinho, Brazil), emulsifying and stabilizing agents (Duas Rodas, Jaraguá do Sul, Brazil. Composition: mixture of fatty acid monoacylglycerols, potassium stearate, sorbitan monostearate and polyoxyethylene sorbitan monostearate), cocoa powder (Marfil, Curitiba, Brazil), concentrated bovine whey protein (80 $\mathrm{g} / 100 \mathrm{~g})$ and concentrated rice protein $(73 \mathrm{~g} / 100 \mathrm{~g}$, Growth Supplements, Bombinhas, Brazil) were used.

Chemicals for HPLC analysis of phenolic compounds were purchased from different suppliers and their purity was $\geq 98 \%$. Gallic acid, 5-caffeoylquinic acid, epicatechin, epicatechin gallate, gallocatechin, epigallocatechin, and epigallocatechin gallate were purchased from Sigma-Aldrich (Espoo, Finland). Procyanidin B2 was purchased from Extrasynthese (Lyon, France). Kaempferol, myricetin and quercetin were acquired from Carl Roth $\mathrm{GmBH}$ (Karlsruhe, Germany). Butylated hydroxyanisole (BHA) and formic acid were obtained from Sigma-Aldrich (Espoo, Finland). Phosphoric acid and hydrochloric acid were obtained from Merck (Darmstadt, Germany) and Fisher Scientific (Vantaa, Finland), respectively. Methanol (LC-MS) was obtained from J.T. Baker (Gliwice, Poland) and acetonitrile (LC-MS) from VWR Chemicals (Helsinki, Finland).

\subsection{Plant material and obtaining the lyophilized mixed extract} (LME)

Organic white tea (Camellia sinensis var. sinensis), fermented rooibos (Aspalathus linearis), and toasted matte (Ilex paraguariensis) were purchased from CLIPPERP (Germany), Matte Leão (Brazil), and Simon Lévelt (Netherlands), respectively. The material was ground, and the particle size standardized on 60 Tyler mesh. A mixture containing $82.9 \%$ white tea, $10.9 \%$ mate tea and $6.2 \%$ rooibos tea was extracted $\left(80^{\circ} \mathrm{C}\right.$ for $\left.10 \mathrm{~min}\right)$ with mineral water at a $1: 50(\mathrm{w} / \mathrm{v})$ ratio, totaling $5 \mathrm{~L}$ of tea (Santos et al., 2018). Then, the aqueous extract was freeze-dried at $1,200 \mu \mathrm{Hg}$ at -50 ${ }^{\circ} \mathrm{C}$ for $120 \mathrm{~h}$ (Terroni LD, model LD1500, São Paulo, Brazil). The lyophilized herbal extract (LME) was stored under vacuum until analysis.

\subsection{Phenolic composition and antioxidant profile of $L M E$}

The total phenolic content was determined by the Prussian blue method and the results are expressed in mg gallic acid equivalents per $100 \mathrm{~g} \mathrm{(mg} \mathrm{GAE} / 100 \mathrm{~g})$. The content of condensed tannins was determined by the method using $\mathrm{H}_{2} \mathrm{SO}_{4}$ and vanillin and expressed in $\mathrm{mg}$ of catechin equivalents per $100 \mathrm{~g}$ ( $\mathrm{mg} \mathrm{CE} / 100 \mathrm{~g})$. The ferric reducing antioxidant power, FRAP, and the free-radical scavenging activity in relation to DPPH radical were performed and expressed in $\mathrm{mg}$ ascorbic acid equivalents per $100 \mathrm{~g} \mathrm{LME} \mathrm{(mg} \mathrm{AAE/100} \mathrm{g).}$ The total reducing capacity, TRC, was evaluated by the modified Folin-Ciocalteu method and expressed in $\mathrm{mg}$ of quercetin equivalents per $100 \mathrm{~g} \mathrm{(mg} \mathrm{QE/100} \mathrm{g).} \mathrm{Analyses} \mathrm{were} \mathrm{performed} \mathrm{in} \mathrm{quad-}$ ruplicate. The description of the analytical methods employed was previously reported by Santos et al. (2018). 
Table 1. Formulation of popsicles according to the protein source and addition of an herbal extract containing antioxidants

\begin{tabular}{|c|c|c|c|}
\hline Formulations & Bovine milk whey protein $(\mathrm{g} / 100 \mathrm{~g})$ & Rice protein (g/100 g) & Lyophilized herbal extract $(\mathrm{g} / 100 \mathrm{~g})^{1}$ \\
\hline F1 & 5 & 0 & 0 \\
\hline F2 & 5 & 0 & 1 \\
\hline F3 & 0 & 5 & 0 \\
\hline F4 & 0 & 5 & 1 \\
\hline F5 & 2.5 & 2.5 & 0 \\
\hline F6 & 2.5 & 2.5 & 1 \\
\hline
\end{tabular}

${ }^{1}$ Herbal extract composed of $82.9 \%$ white tea $+10.9 \%$ mate tea $+6.2 \%$ fermented rooibos tea.

An Acquity UPLC-Xevo G2 QTOF high resolution mass spectrometer (Waters, Milford, MA, USA) operated by Waters MassLynx 4.1 software was used for the characterization of phenolic compounds in LME. Compounds were separated on Waters Acquity $\mathrm{BEH} \mathrm{C}_{18}(1.7 \mu \mathrm{m}, 2.1 \mathrm{~mm} \times 150 \mathrm{~mm})$ column using a gradient of $0.1 \%$ formic acid in $\mathrm{H}_{2} \mathrm{O}$ (A) and of $0.1 \%$ formic acid in acetonitrile (B). The gradient program was as follows: $2 \%$ of $\mathrm{B}$ in $0-2 \mathrm{~min}, 2-75 \%$ of B in $2-27 \mathrm{~min}, 75-99 \%$ of B in $27-32 \mathrm{~min}$, held at $99 \%$ of B for $2 \mathrm{~min}, 99-2 \%$ in $2 \mathrm{~min}$ and held at $2 \%$ of B for $4 \mathrm{~min}$. The flow rate was $0.55 \mathrm{~mL} / \mathrm{min}$, temperature of the column oven was $45^{\circ} \mathrm{C}$, and the injection volume was $1.0 \mu \mathrm{L}$. An electrospray ionization (ESI) was used with capillary voltage of $-1 \mathrm{kV}$ in negative and $+0.5 \mathrm{kV}$ in positive mode. The sampling cone was set to $35 \mathrm{~V}$ and extraction cone to $4 \mathrm{~V}$. The cone and desolvation nitrogen gas flows were 15 and $990 \mathrm{~L} / \mathrm{h}$, respectively. The desolvation temperature was $550{ }^{\circ} \mathrm{C}$ and the source temperature was $150{ }^{\circ} \mathrm{C}$. Argon was used as the collision gas. MS analyses were conducted by data independent acquisition $\left(\mathrm{MS}^{\mathrm{E}}\right)$ centroid data mode in a full scan $m / z \quad 50-1,500$ with $0.2 \mathrm{sec}$ scan time. In the $\mathrm{MS}^{\mathrm{E}}$ function, the precursor ions from the low-collision energy MS-mode were fragmented using high collision energy ramped up from 25 to 45 V (Pihlava et al., 2018).

Several HPLC methods were used for quantification of individual phenolics. LME samples were dissolved in $65 \%$ methanol (aq) and filtered into HPLC ampoules. Phenolic acids were determined by using an Agilent 1290 Infinity Series ultra-high-performance liquid chromatograph (Agilent Technologies, Palo Alto, CA, USA) equipped with a diode array detector and a fluorescence detector. Phenolic acid separation was done with a Zorbax Eclipse Plus $\mathrm{C}_{18}$ $(2.1 \times 50 \mathrm{~mm}, 1.8 \mu \mathrm{m})$ column (Agilent Technologies Inc.) with $\mathrm{a} \mathrm{C}_{18}$ guard column. The temperature of the column oven was set at $35^{\circ} \mathrm{C}$. A gradient elution was employed with a mobile phase consisting of $50 \mathrm{mM} \mathrm{H}_{3} \mathrm{PO}_{4}$ at $\mathrm{pH} 2.5$ (A) and acetonitrile (B) as follows: $5 \%$ of $\mathrm{B}$ in $0-1.2 \mathrm{~min}, 5-15 \%$ of $\mathrm{B}$ in $1.2-4.25 \mathrm{~min}$, $15-20 \%$ of B in $4.25-10 \mathrm{~min}, 20-50 \%$ of B in $10-15 \mathrm{~min}, 50 \%$ of $\mathrm{B}$ in $15-16.2 \mathrm{~min}, 50-5 \%$ of $\mathrm{B}$ in $16.2-17 \mathrm{~min}$, post-time $2 \mathrm{~min}$ before the next injection. The flow rate of the mobile phase was 0.4 $\mathrm{mL} / \mathrm{min}$, and the injection volume was $2.0 \mu \mathrm{L}$. UV spectra of peaks were recorded between 190 and $400 \mathrm{~nm}$.

Flavan-3-ols were determined by the same UHPLC-DAD-FLD device as phenolic acids using the same column. The binary mobile phase consisted of $0.5 \%$ formic acid (A) and acetonitrile (B): $2 \%$ of $\mathrm{B}$ in $0-2 \mathrm{~min}, 2-5 \%$ of $\mathrm{B}$ in $2-5 \mathrm{~min}, 5-15 \%$ of $\mathrm{B}$ in $5-12$ min, $15-20 \%$ of B in $12-15 \mathrm{~min}, 20-35 \%$ of B in $15-20 \mathrm{~min}, 35-$ $90 \%$ of B in $20-21 \mathrm{~min}$, and back to the starting point in $2 \mathrm{~min}$. The post-time was 2 min before the next injection. The flow rate was $0.5 \mathrm{~mL} / \mathrm{min}$ and the injection volume was $2 \mu \mathrm{L}$. Elution was monitored by diode array detection (DAD; $\lambda 1=270 \mathrm{~nm}, \lambda 2=280 \mathrm{~nm})$ and fluorescence detection (FLD; $\lambda \mathrm{ex}=275 \mathrm{~nm}, \lambda \mathrm{em}=324 \mathrm{~nm}$ ).
Flavonols were determined after acid-hydrolysis as aglycons. The LME sample (10-15 mg) was dissolved in $20 \mathrm{~mL}$ of $62.5 \%$ methanol (aq) containing $0.2 \%$ of BHA, after which $5 \mathrm{~mL}$ of $6 \mathrm{M}$ $\mathrm{HCl}$ were added. The sample was refluxed under an inert atmosphere (argon) for $2 \mathrm{~h}$. Hydrolyzed and cooled sample was brought to a volume of $50 \mathrm{~mL}$ and filtered into the HPLC ampoule. An Agilent 1100 HPLC-DAD device equipped with Nova-Pak $\mathrm{C}_{18}$ column $(3.9 \times 150 \mathrm{~mm}, 4 \mu \mathrm{m})$ was used. The binary mobile phase consisted of $50 \mathrm{mmol} / \mathrm{L} \mathrm{H}_{3} \mathrm{PO}_{4}$ at $\mathrm{pH} 2.4$ (A) and methanol (B): $5-58 \%$ of $\mathrm{B}$ in $0-50 \mathrm{~min}, 58-90 \%$ of $\mathrm{B}$ in $50-56 \mathrm{~min}, 90 \%$ of $\mathrm{B}$ in $56-68 \mathrm{~min}, 90-5 \%$ of $\mathrm{B}$ in $68-71 \mathrm{~min}$. The post-time was 10 min before the next injection. The flow rate was $0.9 \mathrm{~mL} / \mathrm{min}$ and the injection volume $10 \mu \mathrm{L}$. UV spectra of peaks were recorded between 190 and $400 \mathrm{~nm}$ and flavonols were quantified at $370 \mathrm{~nm}$.

All phenolic compounds were quantified using calibration curves of authentic compounds when available. 5-Caffeoylquinic acid (chlorogenic acid) was used as the reference standard for all forms of caffeoylquinic acids. Gallolyated dimeric procyanidin was quantified as epicatechin gallate. Results were expressed as $\mathrm{mg} / 100 \mathrm{~g}$ of LME.

\subsection{Popsicle manufacturing}

Six formulations of edible ice cream were prepared with 100 $\mathrm{mL}$ of water, $10 \mathrm{~g} / 100 \mathrm{~g}$ of sucrose, $2 \mathrm{~g} / 100 \mathrm{~g}$ of emulsifying and stabilizing agents, and $4 \mathrm{~g} / 100 \mathrm{~g}$ of cocoa powder as the base formulation. The six popsicle formulations are shown in Table 1.

The technological process applied consisted of mixing all components in a blender (Mondial, Power NL26) with a capacity of 1.5 $\mathrm{L}$ at $500 \mathrm{~W}$ for $5 \mathrm{~min}$. The incorporation of the emulsifying and stabilizing agents and cocoa powder was performed slowly to facilitate dissolution. Subsequently, the formulations were pasteurized at $65{ }^{\circ} \mathrm{C} / 30 \mathrm{~min}$. After cooling to $10{ }^{\circ} \mathrm{C}$ the mixture was beaten in an electric mixer (KitchenAid, Stand Mixer Bowl Kitchen Aid KEA30CEPNA, USA) with a capacity of $4.3 \mathrm{~L}$ at $300 \mathrm{~W}$ for 5 $\mathrm{min}$. Then, the mixture was added in polyvinyl chloride molds and subjected to rapid freezing in an ultra-freezer at $-74{ }^{\circ} \mathrm{C}$. Finally, the popsicles were removed from the molds, individually wrapped and stored until analysis.

\subsection{Proximal composition of formulations added of LME}

To characterize the popsicles with added of lyophilized mixed extract, the contents of protein, moisture and ash were determined according to the AOCS methods $\mathrm{n}^{\circ} .920 .87 ; 925.09 ; 923.03$, respectively (AOAC, 2005). The lipid content was determined according 
to the AOAC method $\mathrm{n}^{\circ} .989 .05$ (AOAC, 1990). The $\mathrm{pH}$, total titratable acidity and total soluble solids were determined according to methods No. 981.12, 942.15 and 932.12, respectively (AOAC, 1997). The carbohydrate + fiber content of edible ice cream formulations was calculated by the difference between 100 and the sum of the protein, fat, moisture and ash content. The average caloric value of edible ice cream was calculated using the factors Atwater (proteins and carbohydrates $=4 \mathrm{kCal} / \mathrm{g}$ and lipids $=9 \mathrm{kCal} / \mathrm{g}$ ), and the results expressed in $\mathrm{Ccal} / 100 \mathrm{~g}$.

\subsection{Total phenolic compounds, total condensed tannins and in vitro antioxidant activity of popsicles}

To determine the total phenolic content and antioxidant activity of the popsicles, an extraction was performed under constant agitation in a vortex tube shaker for $10 \mathrm{~min}$, of $4 \mathrm{~g}$ of the popsicles in the presence of $4 \mathrm{~mL}$ of methanol. Subsequently, the mixture was centrifuged at $700 \mathrm{xg}$ for $20 \mathrm{~min}$, and the upper phase was collected and analyzed immediately. The total phenolic compounds, total condensed tannin content, as well as FRAP activity, antioxidant action against the DPPH radical and total reducing capacity, were evaluated as described in item 2.3, and the results were expressed in $\mathrm{mg}$ of the standard used for each analysis equivalent per $100 \mathrm{~g}$ of popsicle.

\subsection{Sensory analysis}

Sensory analysis was performed according to the approved terms of the Ethics Committee of UEPG, CAAE: 65493717.9.0000.0105. A total of 444 untrained evaluators, 149 men and 295 women between ages of 18 and 50 years were used after signing the informed consent form. The edible ice cream, $15 \mathrm{~g}$, was served in plastic packaging identified with three random digits. The nine-point structured hedonic scale ranging from 1 (extremely disliked) to 9 (extremely liked) was used to assess acceptability in terms of odor, taste, color and overall impression. The acceptance index for each sample was calculated using the average of the global impression attribute multiplied by 100 and divided by the maximum score, that is, 9. The results were expressed as a percentage of acceptance. The acceptance index for each of the 6 formulations was compared using the Marascuillo procedure, based on the $z$ test with $\mathrm{p}<0.05$. Additionally, the evaluators were requested to answer how much more they would pay (R\$ 0 to $2.00-$ US $\$ 0$ to 0.37 ) for a "chocolate popsicle with the addition of extract rich in natural antioxidant compounds" compared to "commercial popsicle without the addition of natural antioxidants", respectively. The evaluators were also asked (yes/no) whether they would buy the popsicle if it was marketed.

\subsection{Statistical analysis}

The analytical methods were performed in triplicate (unless otherwise stated) and the data were presented as mean \pm standard deviation. To compare the responses, differences between the mean values were assessed by the one-way analysis of variance (ANOVA) followed by the Fisher test to compare the means. To compare two samples (presence or absence of extract) the paired $t$-Student test was applied. Probability values lower than 0.05 were used to reject the null hypothesis (Granato et al., 2014). The software TIBCO Statistica v. 13.3 (TIBCO Statistica Inc., USA) was used for all statistical analyzes.

\section{Results and discussion}

\subsection{Phenolic composition and antioxidant activity of the lyo- phylized herbal extract (LME)}

The average total phenolic content in the LME was $30,401 \mathrm{mg}$ $\mathrm{GAE} / 100 \mathrm{~g}$ and the total amount identified by chromatography was $11,736 \mathrm{mg} / 100 \mathrm{~g}$. The condensed tannin content determined in the LME was 6,844 $\mathrm{mg} \mathrm{CE} / 100 \mathrm{~g}$, which is much higher than the total flavan-3-ol content determined by chromatography. Flavonols, which include quercetin, kaempferol and their glucosides accounted for $65.4 \%$, while flavan-3-ols accounted for $21.6 \%$ and phenolic acids for $13.0 \%$ of the total phenolic content in LME (Table 2).

Epigallocatechin, epigallocatechin gallate, gallic acid, and 5-caffeoylquinic acid were the most abundant phenolic compounds in LME. C. sinensis is the major source of tannins, such as flavan-3-ols, and contributed mainly to the total flavan-3-ol content of LME (Zeng et al., 2020). All flavan-3-ols identified in the present study have been previously reported in C. sinensis previously (Jiang et al., 2015; Wang et al., 2012). Fermented rooibos is a source of flavonols and other flavonoids (both aglycons and glucosides), such as isoquercitrin, rutin, pinobanksin, quercetin, isorhamnetin, luteolin, orientin, aspalathin, hyperoside, and vitexin (Santos et al., 2016; Walters et al., 2017). Tea leaves have also been recognized as a rich source of flavonols, especially quercetin, but also kaempferol and myricetin (JeszkaSkowron, et al., 2018; Wang et al., 2012) Roasted mate is a source of caffeoylquinic acid derivatives (3-caffeoylquinic acid, 4-caffeoylquinic acid, and 5-caffeoylquinic acid, dicaffeoylquinic acids), other phenolic acids, and some flavonols, such as rutin, quercetin glucoside, kaempferol-rhamnoglucoside and kaempferol glucoside (Markowicz Bastos et al., 2007; Mateos et al., 2018). Santos et al. (2020) identified hesperidin, epigallocatechin gallate, isoquercitrin, rutin and hesperidin as the main compounds in LME. In addition, methylxanthines, caffeine and theobromine were detected by UHPLC-QTOF in positive mode, but these compounds were not quantified.

LME was evaluated for its in vitro antioxidant capacity by three different methods. FRAP and DPPH values were 70,375 $\pm 2,575$ and $43,189 \pm 630 \mathrm{mg}$ AAE$/ 100 \mathrm{~g}$, respectively. Similarly, the total reducing capacity of LME, which encompasses both lipophilic and watersoluble antioxidants was $43,790 \pm 2,238 \mathrm{mg} \mathrm{QE} / 100 \mathrm{~g}$. Ali et al. (2014) used pomegranate, asparagus, salep orchid and green asparagus powder ( 1 to $4 \mathrm{~g} / 100 \mathrm{~g}$ ) to manufacture ice creams and observed that the antioxidant activity measured by the DPPH and FRAP assays increased in a dose-dependent manner. The antioxidant activity observed in LME is directly related to the content of phenolic compounds. Recently, Santos et al. (2020) observed that LME also presented Folin-Ciocalteu reducing capacity $(\sim 1,800 \mathrm{mg}$ GAE/L of tea) and $\mathrm{Cu}^{2+}$ chelating ability $\left(\sim 72 \%\right.$ of pyrocatechol violet- $\mathrm{Cu}^{2+}$ complex formation). LME was also shown to decrease mechanical hemolysis of human erythrocytes and inhibited the induced oxidation of Wistar's rat brain homogenate. Morais et al. (2020) evaluated the antioxidant activity and bioaccessibility of phenolic compounds in edible flowers-Rosa chinensis Jacq., Torenia fournieri (F.) Lind., Bellis annua L., Clitoria ternatea L., Cosmos sulphureus Cav., Dianthus chinensis L., Begonia tuberhybrida Voss. and Tagetes patula L. and observed high and positive correlation values $(\mathrm{r}=0.90)$ between total phenolic content and FRAP in the methanolic extract.

\subsection{Proximate composition and physicochemical properties of popsicles}

The physicochemical properties and proximate composition of the 


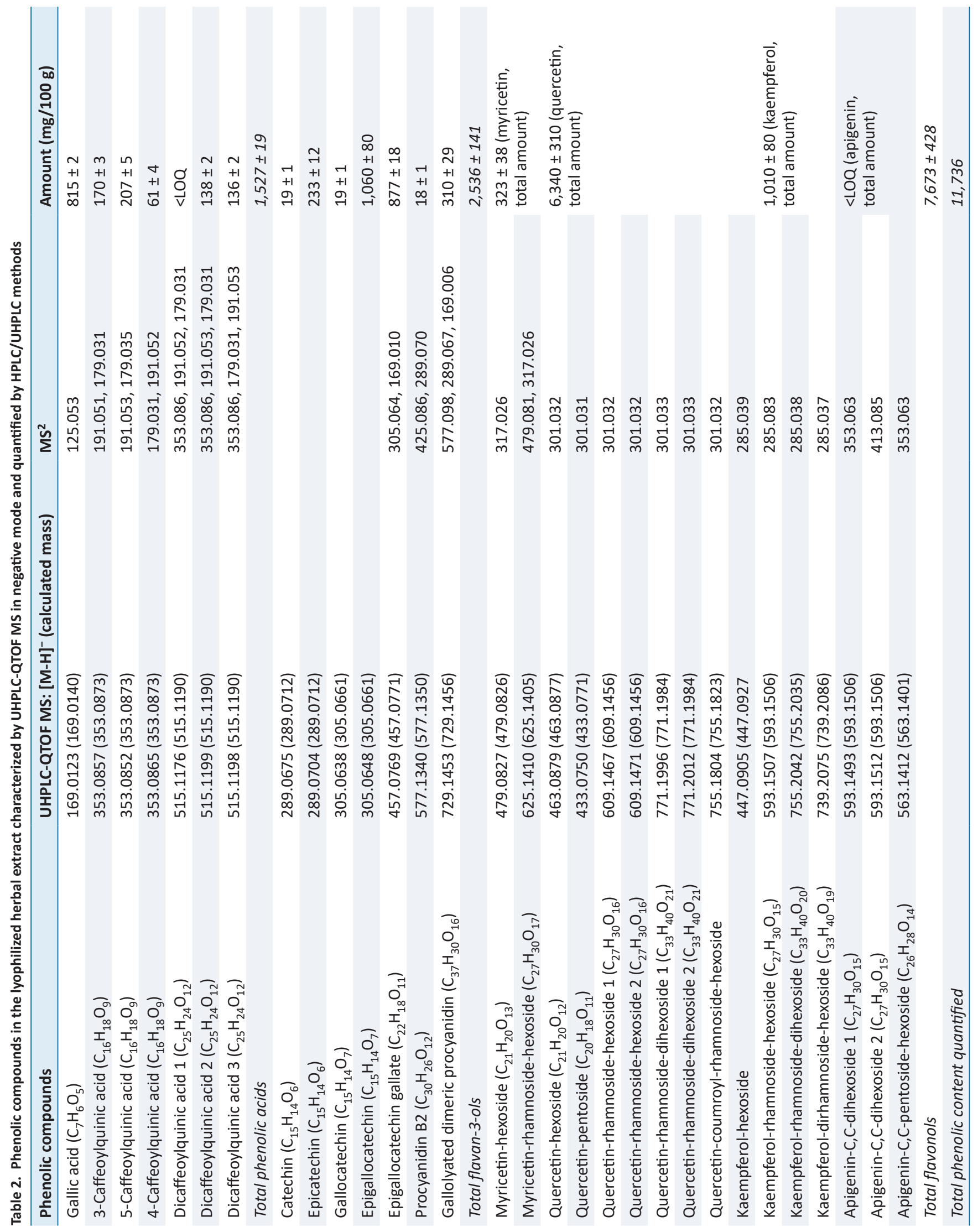


Table 3. Proximal composition and physicochemical properties of popsicles manufactured with different protein sources, with or without the addition of the lyophilized herbal extract (LME) containing antioxidants

\begin{tabular}{|c|c|c|c|}
\hline Evaluated parameters & Bovine whey protein + LME & Rice protein + LME & Bovine whey protein + rice protein + LME \\
\hline \multicolumn{4}{|l|}{ Proximal composition } \\
\hline Lipid (g/100 g) & $1.02 \pm 0.04^{\mathrm{a}}$ & $1.02 \pm 0.03^{a}$ & $1.00 \pm 0.05^{a}$ \\
\hline Ash (g/100 g) & $0.71 \pm 0.07^{a}$ & $0.62 \pm 0.03^{a}$ & $0.47 \pm 0.02^{b}$ \\
\hline Protein $(\mathrm{N} \times 6.38 ; \mathrm{g} / 100 \mathrm{~g})$ & $7.41 \pm 0.47^{a}$ & $7.54 \pm 0.02^{\mathrm{a}}$ & $6.11 \pm 0.13^{b}$ \\
\hline Moisture (g/100 g) & $82.51 \pm 0.14^{a}$ & $76.95 \pm 0.32^{b}$ & $82.90 \pm 1.94^{a}$ \\
\hline Carbohydrates + fibers (g/100 g) & $8.35 \pm 0.57^{b}$ & $13.87 \pm 0.28^{\mathrm{a}}$ & $9.52 \pm 2.02^{\mathrm{ab}}$ \\
\hline Mean energy value (kCal/100 g) & 72 & 95 & 71 \\
\hline \multicolumn{4}{|l|}{ Physicochemical properties } \\
\hline $\mathrm{pH}$ & $6.29 \pm 0.03^{a}$ & $6.71 \pm 0.01^{\mathrm{a}}$ & $6.61 \pm 0.01^{a}$ \\
\hline Titratable acidity (g/100 g) & $0.63 \pm 0.03^{a}$ & $0.18 \pm 0.01^{c}$ & $0.28 \pm 0.01^{b}$ \\
\hline Total soluble solids ( ${ }^{\circ} \mathrm{Brix}$ ) & 24 & 14 & 18 \\
\hline
\end{tabular}

Different letters in the same line represent a statistical difference between popsicles $(p<0.05)$.

popsicles are shown in Table 3. There was no significant difference in the lipid content and $\mathrm{pH}$ between the different formulations $(\mathrm{p}>$ $0.05)$. Regarding the ash and protein contents, there was a significant difference between the popsicles added with only one protein source (either animal or vegetable) in relation to the mixture of the two proteins $(\mathrm{p}<0.05)$. The ash values ranged from $0.71 \pm 0.07$ (bovine whey protein) to $0.47 \pm 0.02 \mathrm{~g} / 100 \mathrm{~g}$ ( $50 \%$ bovine whey protein and $50 \%$ rice protein). Protein contents ranged from $7.54 \pm$ 0.02 (rice protein) to $6.11 \pm 0.13 \mathrm{~g} / 100 \mathrm{~g}(50 \%$ animal protein and $50 \%$ vegetable protein).

Significant difference was observed $(\mathrm{p}<0.05)$ in the moisture content between the popsicle added with rice protein and the other two formulations $(\mathrm{p}<0.05)$, ranging from $82.90 \pm 1.94(50 \%$ bovine whey protein and $50 \%$ rice protein) to $76.95 \pm 0.32$ (rice protein). Regarding the carbohydrate content, a significant difference $(\mathrm{p}<0.05)$ existed between the formulation added with bovine whey protein $(8.35 \pm 0.57 \mathrm{~g} / 100 \mathrm{~g})$ and rice protein $(13.87 \pm$ $0.28 \mathrm{~g} / 100 \mathrm{~g})$. For the total titratable acidity, there was a significant difference $(\mathrm{p}<0.05)$ between all formulations, and values ranged from $0.63 \pm 0.03$ (bovine whey protein) to $0.18 \mathrm{~g} / 100 \mathrm{~g}$ (rice protein).

\subsection{Total phenolic content and condensed tannins in popsicles}

Figure 1a shows the total phenolic content of the popsicles with and without the addition of the LME with animal and/or vegetable protein. Obviously, the higher total phenolic contents $(p<0.001)$ were observed in popsicles added with $1 \mathrm{~g}$ of LME/100 $\mathrm{g}$ of popsicle. It is also observed that the animal and/or vegetable proteins did not negatively affect the solubility and incorporation of phenolic compounds in the popsicle model. Aqueous herbal extracts are recognized sources of phenolic compounds. The incorporation of this type of extract in foods has become an alternative to enhance the antioxidant activity of foods and beverages (Granato et al., 2018).

Figure $1 \mathrm{~b}$ shows the content of total condensed tannins and a similar behavior to that of the total phenolic content was observed. Popsicles with the addition of LME had values between 50 to 55 $\mathrm{mg} \mathrm{CE} / 100 \mathrm{~g}$, while popsicles without the addition of LME did not present tannins. As LME is composed of flavan-3-ols originating from the $C$. sinensis extract, it is plausible that popsicles added with LME would be the source of condensed tannins (Santos et al., 2018).

Our results are in line with those reported by Fidelis et al. (2020) who added a lyophilized tannin-rich extract from camucamu (Myrciaria dubia) seeds in yogurt. This extract had a total phenolic content of 43,598 mg GAE/100 g and a condensed tannins content of $5,766 \mathrm{mg} \mathrm{CE} / 100 \mathrm{~g}$. When added to yogurt (from 0.25 to $1 \mathrm{~g} / 100 \mathrm{~g}$ ), DPPH and FRAP values increased considerably $(\mathrm{p}<0.05)$ in a dose-dependent manner compared to the control (without the tannin-rich extract). Martins et al. (2018) developed popsicles added with concentrated watermelon juice as source of natural flavor and bioactive compounds and found a total phenolic content of $12.5 \mathrm{mg} \mathrm{GAE} / 100 \mathrm{~g}$, lycopene content of about 3 $\mathrm{mg} / 100 \mathrm{~g}$, and antioxidant activity measured by the DPPH assay.

As a final comment on the total phenolic content of foods added with natural extracts, any alleged health benefits to humans should be assessed using clinical trials as it is still debatable whether a higher ingestion of phenolic compounds provides any additional benefits for the overall health (Granato et al. 2020a; Granato et al., 2020b).

\subsection{In vitro antioxidant activity of edible ice cream}

Figure 2 shows the results of the antioxidant activity of the popsicle formulations. Regarding DPPH and FRAP, there was a significant difference $(p<0.001)$ between the different formulations with or without the addition of LME. Regarding the total reducing capacity, the popsicles without the addition of LME did not present any quantifiable antioxidant activity using the applied methodology.

Figure 2a shows that the popsicles added with $1 \mathrm{~g}$ of LME/100 g had a FRAP mean value of $260 \pm 8 \mathrm{mg} \mathrm{AAE} / 100 \mathrm{~g}$, while popsicles without the addition of LME had $28 \pm 1 \mathrm{mg} \mathrm{AAE} / 100 \mathrm{~g}$, thus representing an 8.75-fold increase. This disparity between popsicles with and without the addition of LME was also observed for the DPPH assay (Figure 2b). Popsicle added with $1 \mathrm{~g}$ of LME/100 g had a DPPH mean value of $157 \pm 8 \mathrm{~g}$ of AAE/ $100 \mathrm{~g}$ while a DPPH value of $12 \pm 1 \mathrm{mg} \mathrm{AAE} / 100 \mathrm{~g}$ was obtained for the popsicles without the addition of LME. The total reducing capacity (Figure 2c) ranged from $93 \pm 7 \mathrm{mg} \mathrm{QE} / 100 \mathrm{~g}$ quantified in the edible ice cream added with animal protein to $80 \pm 6 \mathrm{mg} \mathrm{QE} / 100 \mathrm{~g}$ in the ice cream 

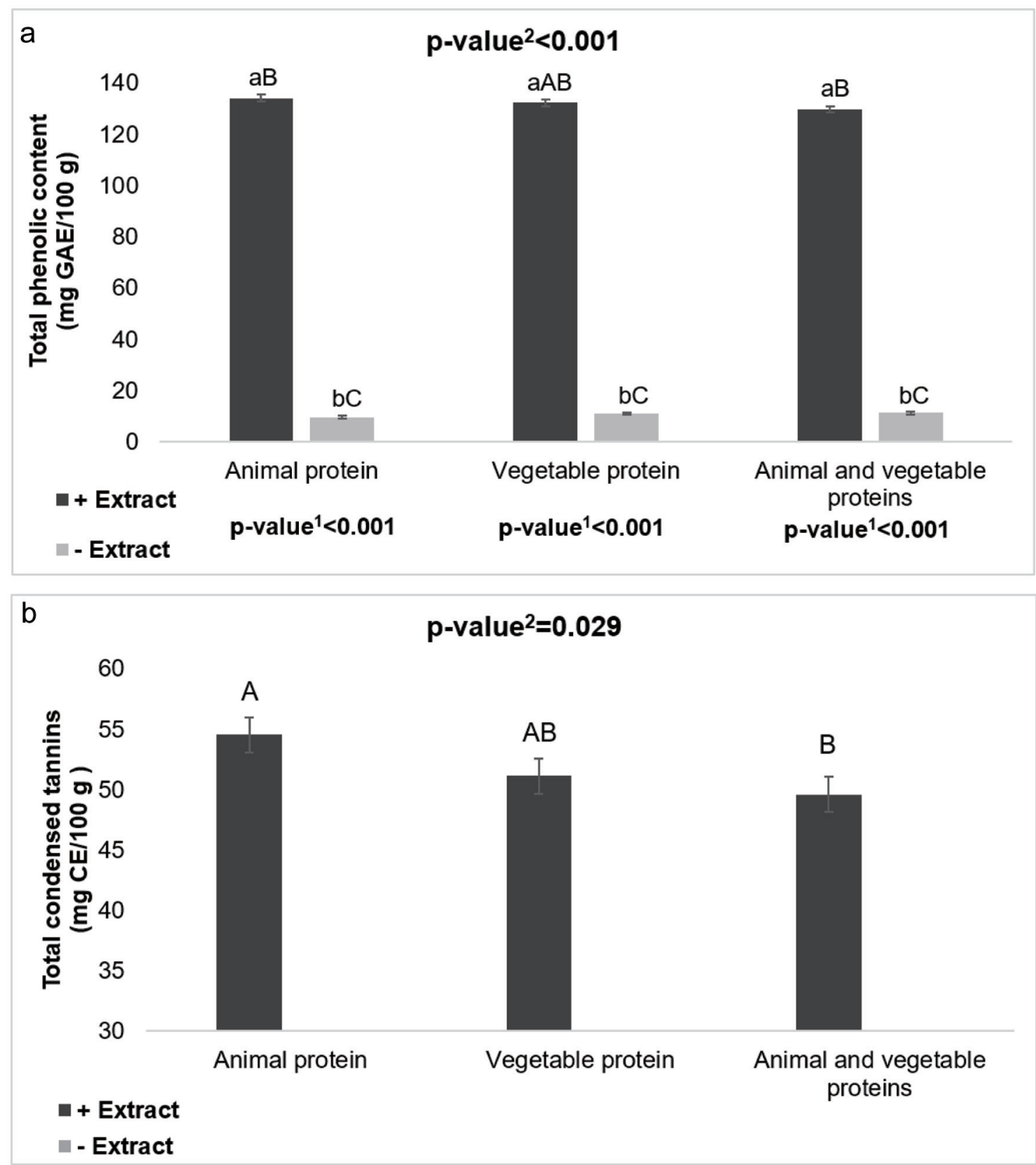

Figure 1. Total phenolic content (a) and condensed tannins (b) of popsicles manufactured with different sources of proteins, with or without the addition of the lyophilized herbal extract (LME). ${ }^{1}$ Probability value obtained by the paired Student-t test; ${ }^{2}$ Probability value obtained by one-way ANOVA; Different lower case letters indicate a significant difference between popsicle manufactured using the same protein source, with and without LME; Different capital letters indicate a significant difference among all popsicle formulations; +extract = popsicle with addition of $1 \mathrm{~g} / 100 \mathrm{~g}$ of lyophilized mixed extract; -extract = popsicle without adding $1 \mathrm{~g} / 100 \mathrm{~g}$ of lyophilized herbal extract.

added with protein animal and vegetable. Similarly, Gremski et al. (2019) added a lyophilized herbal extract ( $1 \mathrm{~g} / 100 \mathrm{~g})$ composed of $70 \%$ green mate (Ilex paraguariensis) and 30\% lemon balm (Melissa officinalis) in ice cream. The herbal extract was mainly composed of flavonoids (quercetin-3-rutinoside, hesperidin and isoquercetin $-11 \mathrm{~g} / 100$ of lyophilized extract) which provided a total phenolic content, DPPH, FRAP, and total reducing capacity of $160 \mathrm{mg} \mathrm{GAE} / 100 \mathrm{~g}, 81 \mathrm{mg} \mathrm{AAE} / 100 \mathrm{~g}, 442 \mathrm{mg} \mathrm{AAE} / 100 \mathrm{~g}$, and $231 \mathrm{mg} \mathrm{QE} / 100 \mathrm{~g}$, respectively.
A similar trend observed herein was obtained by Escher et al. (2019) when a lyophilized extract from Calendula officinalis flower extract was added to a yogurt model. Yogurts added with the flower extract up to $1.5 \mathrm{~g} / 100 \mathrm{~g}$ presented a respective total phenolic content and antioxidant activity (DPPH and total reducing capacity) up to $27 \mathrm{mg} \mathrm{GAE} / 100 \mathrm{~g}, 13 \mathrm{mg} \mathrm{AAE} / 100 \mathrm{~g}$ and 54 $\mathrm{mg}$ QE/100 g.

These results show that the addition of LME increased the antioxidant activity of popsicles formulated with rice and/or bovine 
a

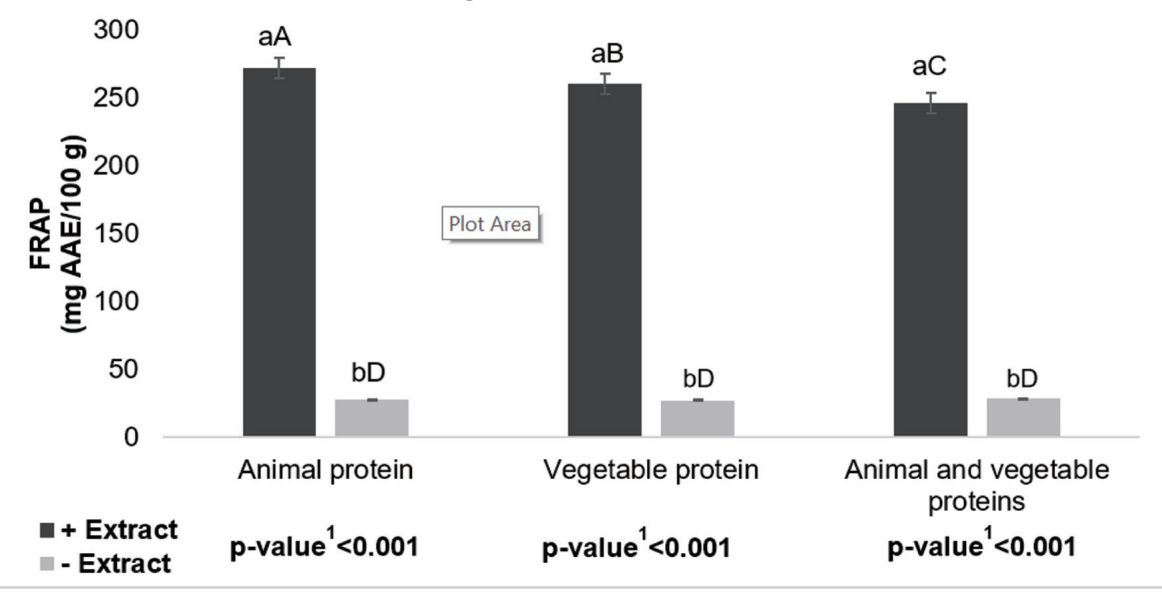

b

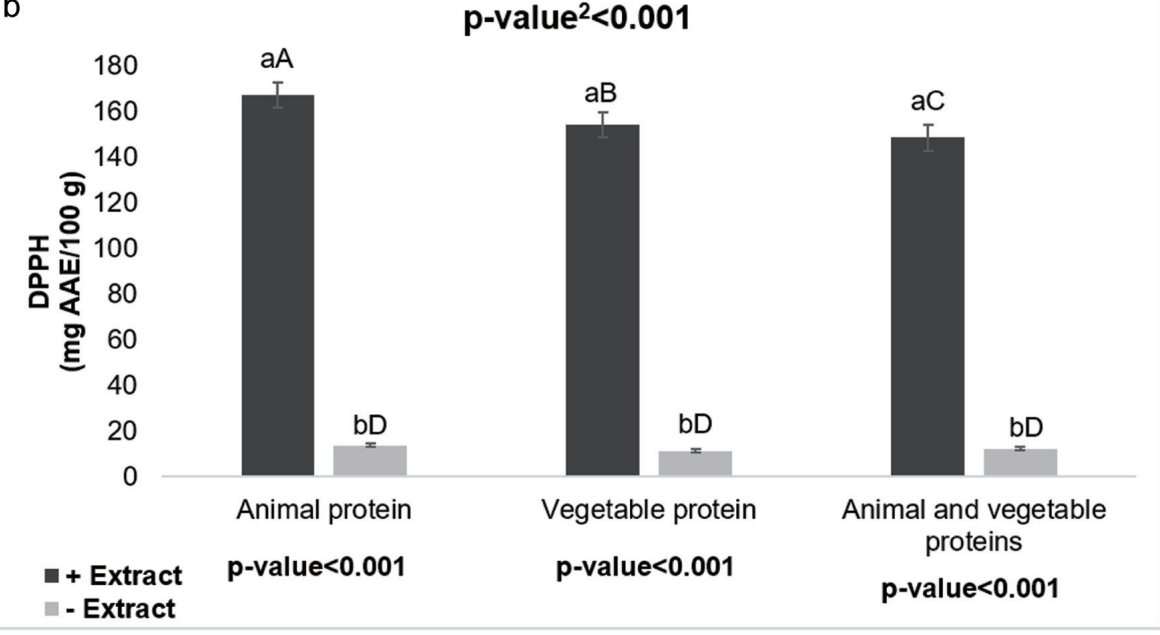

C

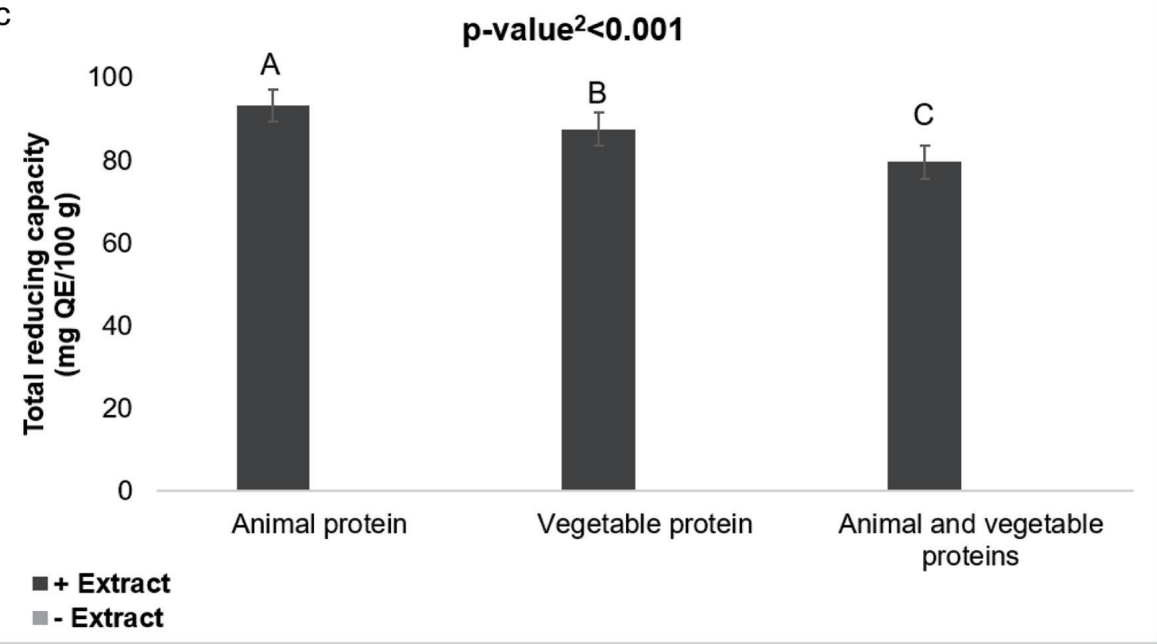

Figure 2. In vitro antioxidant activity (FRAP, A; DPPH, B; TRC, C) of popsicles manufactured with different protein sources, with or without the addition of the lyophilized herbal extract (LME). ${ }^{1}$ Probability value obtained by the paired Student-t test; ${ }^{2}$ Probability value obtained by one-way ANOVA; Different lower case letters indicate a significant difference between popsicle manufactured using the same protein source, with and without LME; Different capital letters indicate a significant difference among all popsicle formulations; +extract = popsicle with addition of $1 \mathrm{~g} / 100 \mathrm{~g}$ of lyophilized mixed extract; - extract = popsicle without adding $1 \mathrm{~g} / 100 \mathrm{~g}$ of lyophilized herbal extract. 
Table 4. : Sensory data of popsicles manufactured with different protein sources, with or without the addition of an herbal extract containing antioxidants.

\begin{tabular}{|c|c|c|c|c|}
\hline Formulations & Odor & Taste & Consistency & Color \\
\hline Bovine whey protein - herbal extract & $7.1 \pm 1.5^{\mathrm{ab}}$ & $8.0 \pm 1.3^{a}$ & $7.9 \pm 1.3^{a}$ & $8.2 \pm 1.0^{\mathrm{a}}$ \\
\hline Bovine whey protein + herbal extract & $7.4 \pm 1.6^{\mathrm{a}}$ & $7.7 \pm 1.3^{\mathrm{ab}}$ & $7.6 \pm 1.4^{\mathrm{ab}}$ & $8.2 \pm 1.2^{\mathrm{a}}$ \\
\hline Rice protein - herbal extract & $6.8 \pm 1.8^{\mathrm{bc}}$ & $6.6 \pm 1.9^{c}$ & $6.5 \pm 1.8^{c}$ & $6.9 \pm 1.7^{b}$ \\
\hline Rice protein + herbal extract & $6.4 \pm 1.9^{c}$ & $5.8 \pm 2.0^{d}$ & $6.3 \pm 2.2^{c}$ & $7.3 \pm 1.7^{b}$ \\
\hline Bovine whey protein + rice protein - herbal extract & $7.5 \pm 1.6^{\mathrm{a}}$ & $7.4 \pm 1.5^{b}$ & $7.3 \pm 1.6^{b}$ & $8.2 \pm 1.3^{a}$ \\
\hline Bovine whey protein + rice protein + herbal extract & $7.1 \pm 1.6^{\mathrm{ab}}$ & $6.8 \pm 1.9^{c}$ & $6.7 \pm 1.9^{c}$ & $8.3 \pm 1.2^{a}$ \\
\hline$p-$ Value $^{1}$ & 0.001 & $<0.001$ & $<0.001$ & $<0.001$ \\
\hline
\end{tabular}

${ }^{1}$ Probability values obtained by one-way ANOVA; Different letters in the same column represent statistical difference between popsicle formulations.

whey protein. Our results clearly show that the incorporation of natural extracts rich in antioxidant compounds in popsicle, which is a product widely consumed by all age groups, is feasible. This is in line with the global trend of consumers looking for foods that have more functional natural compounds and less synthetic additives (Granato et al., 2018; Kooijmans and Flores-Palacios, 2014; Katt and Meixner, 2020).

\subsection{Sensory analysis}

The data for the sensory attributes of the popsicles - liking of odor, flavor, consistency and color-are shown in Table 4. There was a significant difference $(\mathrm{p}<0.05)$ in all parameters evaluated. Formulations F1 and F2, which were added with bovine whey protein, were better perceived by the assessors for all their assessed sensory parameters. These results were similar for popsicles with or without the LME. Popsicles manufactured with rice protein (formulations F3 and F4, respectively) garnered the lowest hedonic scores, and LME negatively impacted on the liking of flavor.

Figure 3 shows the effects of adding $1 \mathrm{~g}$ of LME/100 $\mathrm{g}$ on the acceptance rate of popsicles. It was observed that the addition of LME in formulation did not decrease the overall acceptance of formulations ( $p>0.05)$. Sacchi et al. (2019) developed ice creams added with extra virgin olive oil and found that although the prod- uct had $25 \mathrm{mg} \mathrm{GAE} / \mathrm{kg}$ of total phenolics, it was well accepted by the taste panel for receiving high scores for "cut grass", "aromatic persistence", and "global aromatic intensity". Ice creams added with spray-dried microalgae up to $0.3 \mathrm{~g} / 100 \mathrm{~g}$ (total phenolic content between 150 and $240 \mathrm{mg} \mathrm{GAE} / \mathrm{kg}$ ) did not differ from the control (no addition of microalgae) in terms of overall sensory acceptability and degree of liking of color, structure, taste, odor, melting, texture, and strange taste (Durmaz et al., 2020).

The overall acceptance indices for the popsicle formulations are shown in Figure 3. No significant $(\mathrm{p}=0.354)$ difference in acceptance index was observed between F1 (91\%) and F2 (88\%). Popsicles manufactured with rice protein (F3 and F4) presented the lowest acceptance indices -73 and $69 \%$, respectively. This result shows that the added protein is the determining factor in the acceptance of the product. Kurt and Atalar (2018) used quince seed flour up to $0.75 \mathrm{~g} / 100 \mathrm{~g}$ ( $4.6 \mathrm{~g} / 100 \mathrm{~g}$ of proteins) to develop ice creams and found that the protein content was not associated with the sensory acceptance of the formulations. Additionally, the degree of liking of flavor, texture and appearance was not different $(p>0.05)$ from the control (no addition of quince seed flour). Dos Santos Cruxen et al. (2017) developed ice creams with increased concentrations of butiá (Butia odorata) pulp (30 to 50\%; total phenolic content between 49 and $67 \mathrm{mg}$ GAE/100 g and DPPH values between 17 and $24 \%$ of inhibition). Sensory analysis showed that there was no difference in overall acceptability between treat-

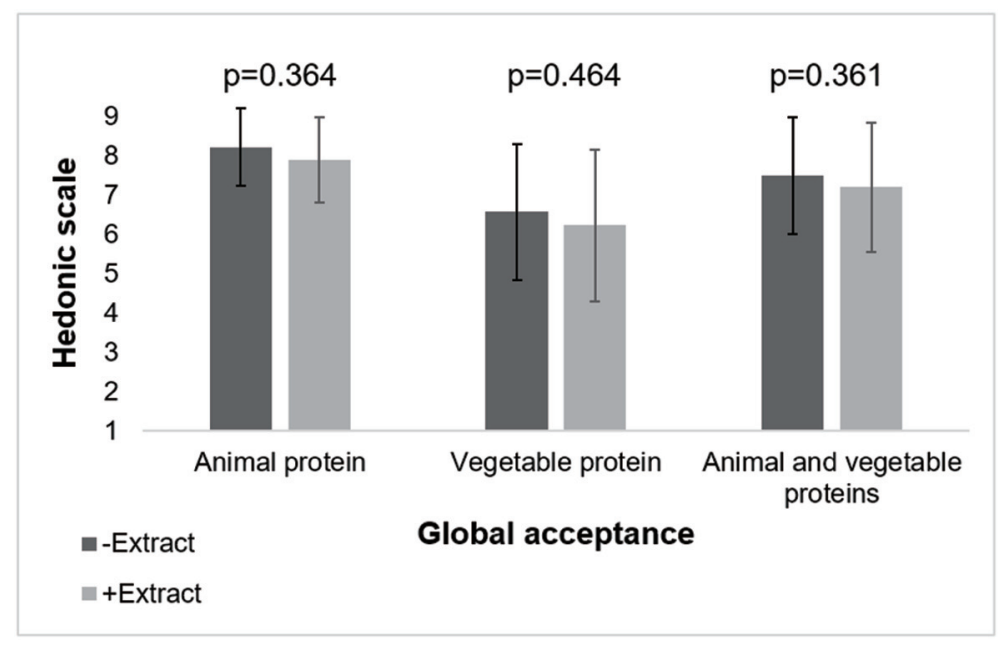

Figure 3. Overall sensory acceptance of popsicle formulations manufactured with different protein sources with or without the addition of the lyophilized herbal extract (LME). Note: The probability values are based on the paired Student- $t$ test. 
ments, but the degree of liking of color and flavor was higher for ice creams added with $50 \%$ of butiá pulp.

When the evaluators were asked about the purchase intention, $77 \%$ responded that they would buy popsicles with added proteins and natural extract. The assessors also gave their opinion on the amount paid more for a $75 \mathrm{~g}$ unit of "chocolate popsicle added with a natural extract rich in antioxidants" (R\$ 0 to 2.00 - US\$ 0 to 0.37 ) compared to a "commercial popsicle without the addition of a natural extract rich in antioxidants" (R\$ 2.00 - US\$ 0.37), respectively. The result was that $90 \%$ of the assessors would pay at least R\$ 0.50 (US\$ 0.09 ) more for the product rich in natural antioxidants. This result highlights the demand of current consumers, who are concerned not only with sensory issues, but also with the presence of natural compounds with possible bioactivities rand possible health benefits of the product.

\section{Conclusions}

The results presented in this work indicates that the addition 1 $\mathrm{g} / 100 \mathrm{~g}$ of the optimized lyophilized extract containing white tea, roasted mate and fermented rooibos in popsicles provides a significant increase in antioxidant compounds, regardless of the added protein. The product formulated with animal protein and added with the optimized extract showed $88 \%$ acceptance of by the consumers, indicating its market potential. Rice protein was shown to be an adequate source of protein for the development of popsicles. Overall, popsicles that are sources of proteins and phenolic compounds may become a potential delivery system of high-quality nutritional proteins and bioactive compounds.

\section{Acknowledgments}

Authors thank the Coordination for the Improvement of Higher Education Personnel (CAPES) for partially funding the work (Finance Code 001). J. S. Santos thanks CAPES/Fundação Araucária for a $\mathrm{PhD}$ scholarship. D. Granato acknowledges the Brazilian National Council for Scientific and Technological Development for a productivity grant (303188/2016-2).

\section{References}

ABIS. Associação Brasileira da Indústria de Sorvete. (2020). Associação Brasileira da Indústria de Sorvete. Disponível em: http://www.abis. com.br/estatistica_producaoeconsumodesorvetesnobrasil.html. Acessado em: 15 de janeiro de 2020.

Adeva-Andany, M.M., Rañal-Muíño, E., Vila-Altesor, M., FernándezFernández, C., Funcasta-Calderón, R., and Castro-Quintela, E. (2019). Dietary habits contribute to define the risk of type 2 diabetes in humans. Clin Nutr. 34: 8-17.

Ali, M.N., Prasad, S.G.M., Gnanaraja, R., Srivastava, P., Ibrahim, M., and Singh, A. (2014). Assess the antioxidant activity of herbal ice cream prepared by using selected medicinal herbs. J. Pharm. Innov. 3: 5759.

AOAC - Association of Official Analytical Chemists. (2005). Official methods of analysis of the AOAC, 18th Ed. AOAC, Arlington, VA.

AOAC - Association of Official Analytical Chemists. (1990). Official Methods of Analisis, Washington, DC.

AOAC - Association of Official Analytical Chemists. (1997). Official Methods of Analisis; Editted by Sidney Williams, 16 ed. AOAC, Arlington, VA.

BRASIL. (2005). Ministério da Saúde. Agência Nacional de Vigilância Sani-

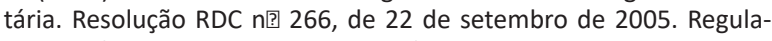
mento técnico para gelados comestíveis e preparados para gelados comestiveis. Diário Oficial da República Federativa do Brasil, Poder Executivo, Brasília, DF, 23 set. 2005.

Dos Santos Cruxen, C.E., Hoffmann, J.F., Zandoná, G.P., Fiorentini, Â.M., Rombaldi, C.V., and Chaves, F.C. (2017). Probiotic butiá (Butia odorata) ice cream: Development, characterization, stability of bioactive compounds, and viability of Bifidobacterium lactis during storage. LWT - Food Sci.Technol. 75: 379-385.

Durmaz, Y., Kilicli, M., Toker, O.S., Konar, N., Palabiyik, I., and Tamtürk, F. (2020). Using spray-dried microalgae in ice cream formulation as a natural colorant: Effect on physicochemical and functional properties. Algal Res. 47: 101811.

Escher, G.B., Borges, L.C., Santos, J.S., Cruz, T.M., Marques, M.B., Do Carmo, M.A.V., Azevedo, L., Furtado, M.M., Sant'ana, A.S., Wen, M., Zhang, L., and Granato, D. (2019). From the field to the pot: phytochemical and functional analyses of Calendula officinalis L. flower for incorporation in an organic yogurt. Antioxidants. 8: 559-582.

Ferdowsian, H.R., and Barnard, N.D. (2009). Effects of plant-based diets on plasma lipids. Am. J. Cardiol. 104: 947-956.

Fidelis, M., De Oliveira, S.M., Santos, J.S., Escher, G.B., Rocha, R.S., Cruz, A.G., Do Carmo, M.A.V., Azevedo, L., Kaneshima, T., Oh, W.Y., Shahidi, F., and Granato, D. (2020). From byproduct to a functional ingredient: camu-camu seed extract (Myrciaria dubia) as an antioxidant agent in a yogurt model. J. Dairy Sci. 103: 1131-1140.

Granato, D., Calado, V.M.A., and Jarvis, B. (2014). Observations on the use of statistical methods in food science and technology. Food Res. Int. 55: 137-149.

Granato, D., Lorenzo, J.M., Bursac Kovačevic, D., Barba, F.J., Cruz, A.G., and Putnik, P. (2020b). Functional foods: product development, technological trends, efficacy testing, and safety. Annu. Rev. Food Sci. Technol. 11: 93-118.

Granato, D., Mocan, A., and Câmara, J.S. (2020a). Is a higher ingestion of phenolic compounds the best dietary strategy? A scientific opinion on the deleterious effects of polyphenols in vivo. Trends Food Sci. Tech. 98: 162-166.

Granato, D., Santos, J.S., Salem, R.D., Mortazavian, A.M., Rocha, R.S., and Cruz, A.G. (2018). Effects of herbal extracts on quality traits of yogurts, cheeses, fermented milks, and ice creams: a technological perspective. Curr Opin Food Sci. 19: 1-7.

Gremski, L.A., Coelho, A.L.K., Santos, J.S., Daguer, H., Molognoni, L., do Prado-Silva, L., Sant'Ana, A.S., Rocha, R.S., Silva, M.C., Cruz, A.G., Azevedo, L., Carmo, M.A.V., Wen, M., Zhang, L., and Granato, D. (2019). Antioxidants-rich ice cream containing herbal extracts and fructooligossaccharides: manufacture, functional and sensory properties. Food chem. 298: 125098.

Jeszka-Skowron, M., Zgola-Grześkowiak, A., and Frankowski, R. (2018). Cistus incanus a promising herbal tea rich in bioactive compounds: LC-MS/MS determination of catechins, flavonols, phenolic acids and alkaloids - A comparison with Camellia sinensis, Rooibos and Hoan Ngoc herbal tea. J. Comp. Food Anal. 74: 71-81.

Jiang, X., Liu, Y., Wu, Y., Tan, H., Meng, F., Wang, Y., Li, M., Zhao, L., Liu, L., Qian, Y., Gao, L., and Xia, T. (2015). Analysis of accumulation patterns and preliminary study on the condensation mechanism of proanthocyanidins in the tea plant [Camellia sinensis]. Sci.Rep. 5: 8742.

Katt, F., and Meixner, O. (2020). A systematic review of drivers influencing consumer willingness to pay for organic food. Trends Food Sci.Tech. 100: 374-388.

Khan, N., and Mukhtar, H. (2019). Tea polyphenols in promotion of human health. Nutrients 11: 39.

Kooijmans, A., and Flores-Palacios, F. (2014). Is eating science or common sense? Knowledge about "natural foods" among self-identified "natural food" consumers, vendors and producers in rural and urban Mexico. Appetite 81: $37-43$.

Kurt, A., and Atalar, I. (2018). Effects of quince seed on the rheological, structural and sensory characteristics of ice cream. Food Hydrocoll. 8: 186-195.

Markowicz Bastos, D.H., Saldanha, L.A., Catharino, R.R., Sawaya, A.C.H.F., Cunha, I.B.S., Carvalho, P.O., and Eberlin, M.N. (2007). Phenolic Antioxidants Identified by ESI-MS from Yerba Maté (Ilex paraguariensis) and Green Tea (Camelia sinensis) Extracts. Molecules 12: 423-432.

Martins, C.P., Ferreira, M.V.S., Esmerino, E.A., Moraes, J., Pimentel, T.C., Rocha, R.S., Freitas, M.Q., Santos, J.S., Ranadheera, C.S., Rosa, L.S., 
Teodoro, A.J., Mathias, S.P., Silva, M.C., Raices, R.S.L., Couto, S.R.M., Granato, D., and Cruz, A.G. (2018). Chemical, sensory, and functional properties of whey-based popsicles manufactured with watermelon juice concentrated at different temperatures. Food Chem. 255: 5866.

Mateos, R., Baeza, G., Sarriá, B., and Bravo, L. (2018). Improved LC-MSn characterization of hydroxycinnamic acid derivatives and flavonols in different commercial mate (Ilex paraguariensis) brands. Quantification of polyphenols, methylxanthines, and antioxidant activity. Food Chem. 242: 232-241.

Öztürk, H.İ., Demirci, T., and Akın, N. (2018). Production of functional probiotic ice creams with white and dark blue fruits of Myrtus communis: The comparison of the prebiotic potentials on Lactobacillus casei 431 and functional characteristics. LWT - Food Sci.Technol. 90: 339-345.

Patel, H., Chandra, S., Alexander, S., Soble, J., and Williams, K.A. (2017). Plant-based nutrition: An essential component of cardiovascular disease prevention and management. Curr. Cardiol. Rep. 19: 104.

Pihlava, J.-M., Hellström, J., Kurtelius, K., and Mattila, P. (2018). Flavonoids, anthocyanins, phenolamides, benzoxazinoids, lignans and alkylresorcinols in rye (Secale cereale) and some rye products. J. Cereal. Sci. 79: 183-192.

Sacchi, R., Caporaso, N., Squadrilli, G.A., Paduano, A., Ambrosino, M.L., Cavella, S., and Genovese, A. (2019). Sensory profile, biophenolic and volatile compounds of an artisanal ice cream ('gelato') functionalised using extra virgin olive oil. Int. J. Gastron. Food Sci. 18: 100173.

Santos, J.S., Deolindo, C.T.P., Fujita, A., Genovese, M.I., Daguer, H., Valese, A., Marques, M.B., Rosso, N.D., and Granato, D. (2016). Effects of time and extraction temperature on phenolic composition and functional properties of red rooibos (Aspalathus linearis). Food Res. Int. 89: 476-487.

Santos, J.S., Escher, G.B., Do Carmo, M.V., Azevedo, L., Marques, M.B., Daguer, H., Molognoni, L., Genovese, M.I., Wen, M., Zhang, L., Oh, W.Y., Shahidi, L., and Granato, D. (2020). A new analytical concept based on chemistry and toxicology for herbal extracts analysis: from phenolic composition to bioactivity. Food Res. Int. 132: 109090.

Santos, J.S., Deolindo, C.T., Hoffmann, J.F., Chaves, F.C., Do Prado-Silva, L. Sant'ana, A.S., Azevedoe, L., Carmo, M.A.V., and Granato, D. (2018). Optimized Camellia sinensis var. sinensis, Ilex paraguariensis, and Aspalathus linearis blend presents high antioxidant and antiproliferative activities in a beverage model. Food Chem. 254: 348-358.

Satija, A., and Hu, F.B. (2018). Plant-based diets and cardiovascular health. Trends Cardiovasc. Med. 28: 437-441.

Walters, N.A., Villiers, A., Joubert, E., and de Beer, D. (2017). Phenolic profiling of rooibos using off-line comprehensive normal phase countercurrent chromatography $\times$ reversed phase liquid chromatography. J. Chromatogr. A. 1490: 102-114.

Wang, Y.S., Gao, L.P., Shan, Y., Liu, J., and Tian, Y.W. (2012). Influence of shade on flavonoid biosynthesis in tea (Camellia sinensis (L.) $\mathrm{O}$. Kuntze). Sci. Hort. 141: 7-16. 